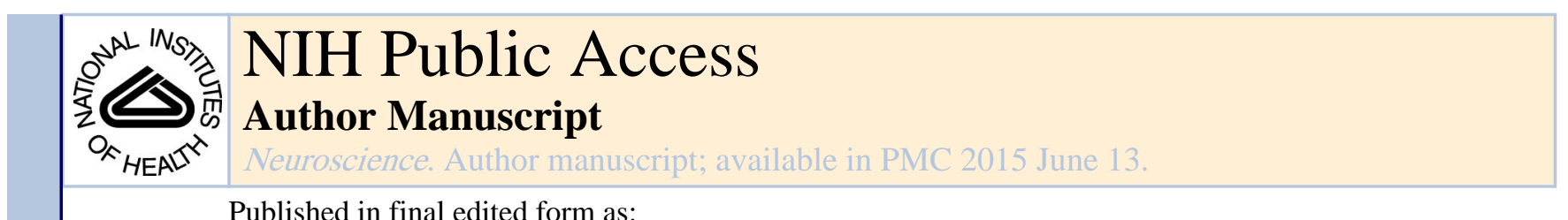

Published in final edited form as:

Neuroscience. 2014 June 13; 270: 139-147. doi:10.1016/j.neuroscience.2014.04.006.

\title{
INSULIN RESISTANCE AND GRAY MATTER VOLUME IN NEURODEGENERATIVE DISEASE
}

\author{
J. K. MORRIS ${ }^{a, b}$, E. D. VIDONI ${ }^{a, b}$, R. D. PEREA ${ }^{a, b}$, R. RADA ${ }^{b}$, D. K. JOHNSONc, K. LYONS ${ }^{a}$, \\ R. PAHWA ${ }^{a}$, J. M. BURNS ${ }^{a, b}$, and R. A. HONEA ${ }^{a, b,{ }^{*}}$ \\ J. K. MORRIS: jmorris2@kumc.edu; E. D. VIDONI: evidoni@kumc.edu; R. D. PEREA: rperea@kumc.edu; R. RADA: \\ rrada@kumc.edu; D. K. JOHNSON: dkj@ku.edu; K. LYONS: klyons@kumc.edu; R. PAHWA: rpahwa@kumc.edu; J. M. \\ BURNS: jburns2@kumc.edu; R. A. HONEA: rhonea@kumc.edu \\ aDepartment of Neurology, University of Kansas Medical Center, Kansas City, KS, United States \\ ${ }^{b}$ Alzheimer's Disease Center, University of Kansas Medical Center, Kansas City, KS, United \\ States
}

'Department of Psychology, University of Kansas, Lawrence, KS, United States

\section{Abstract}

The goal of this study was to compare insulin resistance in aging and aging-related neurodegenerative diseases, and to determine the relationship between insulin resistance and gray matter volume (GMV) in each cohort using an unbiased, voxel-based approach. Insulin resistance was estimated in apparently healthy elderly control $(\mathrm{HC}, n=21)$ and neurodegenerative disease (Alzheimer's disease (AD), $n=20$; Parkinson's disease (PD), $n=22$ ) groups using Homeostasis Model Assessment of Insulin Resistance 2 (HOMA2) and intravenous glucose tolerance test (IVGTT). HOMA2 and GMV were assessed within groups through General Linear Model multiple regression. We found that HOMA2 was increased in both $\mathrm{AD}$ and PD compared to the $\mathrm{HC}$ group (HC vs. $\mathrm{AD}, p=0.002$, $\mathrm{HC}$ vs. $\mathrm{PD}, p=0.003$ ), although only $\mathrm{AD}$ subjects exhibited increased fasting glucose $(p=0.005)$. Furthermore, our voxel-based morphometry analysis revealed that HOMA2 was related to GMV in all cohorts in a region-specific manner $(p<0.001$, uncorrected). Significant relationships were observed in the medial prefrontal cortex (HC), medial temporal regions (AD), and parietal regions (PD). Finally, the directionality of the relationship between HOMA2 and GMV was disease-specific. Both HC and AD subjects exhibited negative relationships between HOMA2 and brain volume (increased HOMA2 associated with decreased brain volume), while a positive relationship was observed in PD. This cross-sectional study suggests that insulin resistance is increased in neurodegenerative disease, and that individuals with $\mathrm{AD}$ appear to have more severe metabolic dysfunction than individuals with PD or PD dementia.

(C) 2014 IBRO.Published by Elsevier Ltd. All rights reserved.

*Correspondence to: R. A. Honea, Department of Neurology, University of Kansas School of Medicine, 4350 Shawnee Mission Parkway, Fairway, KS 66205, United States. Tel: +1-913-945-5038; fax: +1-913-945-5035.

AUTHOR CONTRIBUTIONS

Morris: data processing, statistical analysis, writing. Vidoni: data collection, writing. Perea: data processing, imaging. Rada: data processing, imaging. Johnson: cognitive testing. Lyons: clinical assessment. Pahwa: clinical assessment. Burns: clinical assessment, data collection, writing. Honea: data processing, statistical analysis, writing.

DISCLOSURES

The authors report no conflicts of interest. 


\section{Keywords}

insulin resistance; Alzheimer's disease; Parkinson's disease; dementia; metabolism; glucose tolerance

\section{INTRODUCTION}

Insulin is most widely recognized for its prominent role in glucose clearance from blood.

However, insulin signaling also modulates a wide variety of other cellular processes, including neurotransmission, vesicular trafficking, exocytosis, and cell survival (Wan et al., 1997; Gasparini et al., 2001; van der Heide et al., 2006; Jewell et al., 2011). While it is difficult to directly measure insulin resistance in the brain in vivo, studies on post-mortem tissue have shown markers of insulin resistance in both Alzheimer's Disease (AD) and Parkinson's Disease (PD) brains (Takahashi et al., 1996; Steen et al., 2005; Lee et al., 2009; Moloney et al., 2010; Liu et al., 2011). In fact, overcoming insulin resistance in AD is the basis for clinical trials of intranasal insulin. These trials have shown improvements in cognitive outcomes in individuals who receive intranasal insulin for mild AD (Reger et al., 2008; Craft et al., 2012). These findings provide a rationale for additional studies of the relationship between insulin resistance and neurodegeneration.

Although important cellular functions are set into motion by insulin signaling and interrupted by insulin resistance, the degree to which insulin resistance contributes to the development of neurodegenerative disease is contentious (Simon et al., 2007; Thambisetty et al., 2013) and an area of active research. The most convincing evidence for a role of insulin resistance in the neurodegenerative process stems from numerous reports that diabetes increases both AD (Ott et al., 1999; Xu et al., 2009; Cheng et al., 2011) and PD (Hu et al., 2007; Schernhammer et al., 2011; Xu et al., 2011) risk. It has thus been proposed that insulin resistance is a common underlying mechanism in neurodegenerative disease (Ristow, 2004). However, clinical studies that compare the degree of insulin resistance across neurodegenerative disease cohorts are lacking, and a direct comparison of metabolic function between the two most common neurodegenerative diseases, $\mathrm{AD}$ and PD, has not been performed.

Only two previous studies have assessed the relationship between homeostasis model assessment of insulin resistance 2 (HOMA2) and brain atrophy. One study examined in late middle-aged, cognitively normal subjects (Willette et al., 2013), while the other focused on cognitively healthy elderly (Benedict et al., 2012). Although the latter study analyzed a subgroup of cognitively- impaired individuals, these subjects were not diagnosed with AD or any other dementia. There have been no studies to assess the relationship between gray matter volume (GMV) and HOMA2 in AD or PD using Voxel-Based Morphometry (VBM), which allows for analyses across the whole brain with minimal user bias. This is also the first study to compare insulin resistance between $\mathrm{AD}$ and PD. Both diabetes and hyperinsulinemia are associated with changes in brain structure, including whole-brain (Araki et al., 1994) and medial temporal atrophy (den Heijer et al., 2003), and both patterns have been associated with accelerated aging and neurodegeneration. Insulin resistance has 
been linked with greater atrophy rates in cognitively normal subjects (Benedict et al., 2012; Willette et al., 2013), and in non-diabetic AD subjects, increased insulin response was positively associated with longitudinal brain volume (Burns et al., 2012). The relationship between insulin resistance and brain volume is unexplored in PD. Because these neurodegenerative diseases may not elicit the same metabolic profile, our primary goal was to characterize these cohorts and understand the relative relationships between metabolic function (insulin resistance) and diagnosis, and as an additional approach to analyze the impact of metabolic function on brain structure. Due to the role of insulin as a growth factor and growing literature characterizing insulin resistance as a risk factor for neurodegeneration, we hypothesized that insulin resistance will be different between neurodegenerative disease groups, as well as related to decreased GMV in individuals with neurodegenerative disease.

\section{EXPERIMENTAL PROCEDURES}

\section{Standard protocol approvals, registrations, and patient consents}

This study was approved by the University of Kansas Medical Center's Institutional Review Board. All participants in this study provided informed consent according to institutional guidelines and this project was performed in accordance with the Declaration of Helsinki. Exclusion criteria included diabetes diagnosis or the use of diabetic medications.

\section{Clinical assessment and diagnosis}

Apparently healthy elderly control (HC; $n=21)$ and $\mathrm{AD}(n=20)$ subjects over the age of 65 were randomly selected from the KU Brain Aging Project and screened for eligibility. Participants were recruited from a referral-based memory clinic and by media appeals. The goal of the KU Brain Aging Project was to evaluate the role of cardiorespiratory fitness and metabolism in aging and AD, and has been described previously (Burns et al., 2007, 2011). $\mathrm{AD}$ diagnosis required gradual onset of cognitive symptoms and progression of memory impairment in addition to at least one other cognitive and functional domain (McKhann et al., 1984). The presence or absence of dementia was evaluated by a trained clinician that included a Clinical Dementia Rating (CDR) (Morris, 1993). All HC subjects had a Global CDR of 0 and were deemed cognitively normal by a clinician, while AD participants had a Global CDR of 1. PD subjects $(n=22)$ were recruited from the Parkinson's Disease and Movement Disorder Center at the University of Kansas Medical Center. Patients were diagnosed with idiopathic PD by a neurologist specializing in movement disorders based on United Kingdom Brain Bank Criteria (Hughes et al., 1992). Ten of the 22 PD subjects exhibited dementia (PDD). Diagnostic criteria for PDD were based on recommendations from the Movement Disorder Society Task Force for Level 1 testing (Dubois et al., 2007). Extrapyramidal signs were assessed using the motor subscale of the Unified Parkinson's Disease Rating Scale (UPDRS).

\section{Assessment of cognitive and motor function}

Neuropsychological assessment was performed by psychometricians and included tests from the Uniform Data Set (UDS) used by the national network of Alzheimer's Disease Centers. A normative calculator for this test battery has been published to allow calculation of 
demographically adjusted norms (Shirk et al., 2011). Data from over 3000 cognitively normal individuals that were collected by the National Alzheimer's Coordinating Center during the first 2 years of the use of the UDS were used to develop this tool (Weintraub et al., 2009). For our study, we used this tool to compute sex, age, and education-adjusted scores for each test. We computed a "global cognition" score, by averaging the normed scores from all individual tests in the UDS Neuropsychologic Test Battery, and "domain" scores by averaging scores from UDS tests that fell into the cognitive domains of memory (Logical Memory Immediate and Delayed Recall), language (Verbal Fluency and Boston Naming Test), attention (Digit Span Forward and Digit Span Backward), and executive function/processing speed (Trailmaking Test B, Digit Symbol test) (Weintraub et al., 2009). Motor function was assessed using the UPDRS (Ramaker et al., 2002).

\section{Assessment of insulin resistance}

HOMA2 calculation-The primary measure of insulin resistance was HOMA2. HOMA2 is an updated version of the HOMA-IR but allows for an interactive model of the dynamic relationship between insulin and glucose. Because insulin secretion does not change linearly at increasing fasting glucose levels, HOMA2 utilizes nonlinear modeling and assumes a feedback loop between liver and $\beta$-cells. HOMA2 considers both hepatic and muscle insulin resistance and has been reviewed previously (Wallace et al., 2004). The HOMA2 calculator is available for download from the University of Oxford (http://www.dtu.ox.ac.uk/ homacalculator/index.php) (Levy et al., 1998). Additional measures derived from fasting glucose and insulin measures were $\beta$-cell function $(\% B)$, fasting glucose $(\mathrm{FG})$ and fasting insulin (FI).

Intravenous glucose tolerance test (IVGTT)—High fasting glucose values primarily reflect hepatic insulin resistance (Turner and Holman, 1976), while glucose tolerance tests characterize both skeletal muscle and hepatic insulin resistance (Abdul-Ghani et al., 2006). To further explore systemic metabolic function, an IVGTT was performed following a 12-h fast. A IV glucose bolus $(0.3 \mathrm{~g} / \mathrm{kg})$ was delivered at Time 0 . Blood samples were collected at $-5,1,3,5,10,15,20,30,40,50,60,90$, and $120 \mathrm{~min}$ for the determination of glucose and insulin levels. Area under the curve was computed for glucose (gAUC) and insulin (iAUC).

\section{Neuroimaging}

General MRI acquisition procedures-Structural MRI was obtained using a Siemens 3.0 Tesla Allegra MRI scanner at the Hoglund Brain Imaging Center. High-resolution T1weighted (MPRAGE) images were obtained and a T1-weighted axial slice-based structural scan was acquired (repetition time/echo time $[\mathrm{TR} / \mathrm{TE}]=23 / 4 \mathrm{~ms}$, flip angle $=90^{\circ}$, field of view $[$ FOV $]=192 \mathrm{~mm}$, matrix $=256 \times 256$, slice thickness $=3 \mathrm{~mm}, 0.5$ skip, in-plane resolution $=1 \times 1 \mathrm{~mm}$ ). One individual in the PD group was not able to complete the scan sequence, thus our imaging data reflect data from 21 PD subjects.

Voxel-based morphometry (VBM)—Data analysis for 60 subjects was performed using Statistical Parametric Mapping version 8 (SPM8) algorithms (Wellcome Department of Cognitive Neurology, London, UK) running under MATLAB 7.2 (The MathWorks, Natick, MA, USA) on Linux. Processing for VBM was done by first creating a sample-specific 
DARTEL template (Diffeomorphic Anatomical Registration Through Exponentiated Lie algebra) (Ashburner, 2007). High-dimensional spatial normalization was then used to normalize images to the DARTEL template, and the unified segmentation ("New Segment") model in SPM8 (Ashburner and Friston, 2005) to output warped, modulated, segmented images. Final images were smoothed with a 10-mm isotropic Gaussian kernel. GMV, white matter volume (WMV), and cerebrospinal fluid volumes (CSF) from the segmentations were used to calculate total intracranial volume (TICV).

A General Linear Model (GLM) multiple regression analysis was used to examine the relationship between HOMA2 and GMV differences within groups (HC, AD, and combined PD groups), including age and sex as confounding variables, and total intracranial volume as a global variable. In addition in the VBM analysis of PD subjects, we also did a second analysis including a covariate for the presence of dementia to test whether HOMA2 brain effects were driven only by subjects with PD dementia. We used a log-transformed HOMA2 for VBM statistical analysis since HOMA2 was not normally distributed. Voxels are reported with reference to the Montreal Neurological Institute standard space within SPM8 (Honea et al., 2008). For all analyses, results were considered significant at $p<.001$ uncorrected, with a cluster size of greater than 100 voxels $(k>100)$. This was chosen as analyses were done within diagnosis groups and thus had a lower power to detect smaller brain relationships with HOMA2. Finally, we examined the relationship of HOMA2 with medial temporal lobe volume. The small-volume correction (SVC), the bilateral hippocampus and bilateral parahippocampus combined, were derived from the Wake Forest University Pickatlas (http://www.fmri.wfubmc.edu). This region of interest was preselected as insulin studies in neurodegenerative disease have suggested involvement of hippocampal structures in metabolic dysfunction (Burns et al., 2007, 2011). To correct for multiple comparisons in the SVC analysis, results were considered significant at $p<.05 \mathrm{FWE}$ corrected.

\section{Statistical analyses}

Analyses were performed using SPSS 20. Normality testing (Shapiro-Willk) was performed and metabolic variables that were non-normally distributed (HOMA2, fasting insulin and fasting glucose) were log-transformed prior to statistical analysis. Normative cognitive scores were used in statistical analyses. A one-way analysis of variance (ANOVA) was used to assess differences between diagnosis groups, and post hoc comparisons were performed using the Least-Significant Difference (LSD) test. Categorical variables were presented as frequency and percent, and analyzed using Chi square analysis. Relationships between cognitive function, motor function, and HOMA2 were assessed using multiple linear regression. All analyses were controlled for age and sex.

\section{RESULTS \\ Demographics}

A total of 63 individuals ( $\mathrm{HC}(n=21), \mathrm{AD}(n=20), \mathrm{PD}(n=22))$ were included in the current study. There was no difference in sex, age, or education between groups (Table 1). 


\section{Fasting metabolic measures}

Subjects with neurodegenerative disease had greater insulin resistance (HOMA2; $F=7.1, p$ $=0.002$ ) than $\mathrm{HC}$ subjects (HC vs. AD, $p=0.002 ; \mathrm{HC}$ vs. PD, $p=0.003$ ) (Table 2). Fasting glucose was also different between groups $(F=7.4, p=0.001)$, but post hoc analyses revealed that this increase was only present in AD subjects, who had higher glucose levels than both HC ( $p=0.016)$ and PD groups $(p=0.004)$. Fasting insulin levels were different between groups $(F=6.8, p=0.002)$, with both $\mathrm{AD}(p=0.002)$ and $\mathrm{PD}(p=0.003)$ exhibiting higher levels than $\mathrm{HC}$ subjects. Interestingly, $\beta$-cell function also differed between groups $(F=5.6, p=0.006)$. This difference was driven by PD subjects, who exhibited higher $\beta$-cell function than $\mathrm{HC}$ subjects $(p=0.001)$, while AD subjects did not ( $p$ $=0.128)$.

\section{Glucose tolerance testing}

Glucose and insulin response to a glucose bolus were examined using IVGTT. Glucose area under the curve (gAUC) was significantly different between groups $(F=3.25, p=0.04)$ (Table 2), as AD subjects exhibited significantly higher gAUC than PD subjects $(p=0.033)$. Insulin area under the curve (iAUC) was also different between groups ( $F=5.9, p=0.005$ ). As expected, $\mathrm{AD}$ subjects did not exhibit an increase in iAUC compared to $\mathrm{HC}$ subjects, while PD subjects had increased iAUC than the HC group $(p=0.002)$. A comparison of metabolic differences between groups is shown in Table 3 .

\section{Anthropometric and cardiovascular measures}

Subjects did not differ on body weight or body mass index between groups (Table 2). The number of subjects who met criteria for hypertension (blood pressure 140/90 $\mathrm{mmHg}$ and above) was also not different between groups. However, there was a significant difference in systolic blood pressure between groups $(p=0.028)$, with individuals with $\mathrm{AD}$ having higher systolic BP than individuals with PD $(p=0.013)$.

\section{Insulin resistance (HOMA2) and GMV}

In HC subjects, increased HOMA2 was associated with less GMV in the right medial frontal cortex (Fig. 1, Table 4). In AD subjects, increased HOMA2 was associated with less GMV in the hippocampus/parahippocampus, as well as the postcentral gyrus, inferior temporal cortex, fusiform gyrus, and cerebellum (Fig. 1, Table 4). Individuals with PD who had increased HOMA2 actually exhibited higher GMV than those with lower HOMA2 in the left inferior parietal region (Fig. 1, Table 4). This region remained significant in our secondary analysis using PD dementia status as an additional covariate. In the SVC analysis, only AD had a significant relationship between HOMA2 and medial temporal lobe volume; HOMA2 was associated with less GMV in the bilateral hippocampal/parahippocampal cortices $(p<$. 05 FWE corrected).

\section{Motor function and cognitive testing}

Higher HOMA2 was associated with lower UPDRS score $(B=-0.823, p=0.002)$. Higher fasting insulin $(B=-0.824, p=0.002)$ and increased $\beta$-cell function $(\% B, B=-0.759, p=$ 0.008 ) were also associated with lower UPDRS score, while higher fasting glucose was not 
( $B=-0.260, p=0.358)$. On cognitive testing, $\mathrm{AD}$ and $\mathrm{PD}$ subjects scored worse than controls overall (global cognition) and on tests of memory and executive function $(p<0.05$ for all, Table 1). Only AD subjects performed more poorly than controls on tests of language, and AD subjects also performed worse than PD individuals on tests of memory and language. Scores did not differ on tests of attention across groups. We also examined the relationship between HOMA2 and global cognition, but there was no correlation between insulin resistance and cognitive function in any groups.

\section{Medication use}

We examined the use of medications to assess the possible impact on our findings. There was no difference in the use of statins, selective serotonin reuptake inhibitors (SSRI's), or NMDA receptor agonists between groups. As expected, significantly more PD individuals used Levodopa (90.9\%; $p<0.001)$ and Dopamine receptor agonists $(31.8 \% ; p<0.001)$ than other groups (no ND or AD subjects used these medications). On the contrary, more $\mathrm{AD}$ subjects used competitive cholinesterase inhibitors (77.3\%) compared to PD subjects $(27.3 \%)$ or ND subjects $(0 \% ; p<0.001)$.

\section{DISCUSSION}

This study characterized insulin resistance in $\mathrm{AD}, \mathrm{PD}$, and apparently healthy control subjects. We found that both groups of subjects with neurodegenerative disease exhibited higher HOMA2 compared to HC subjects. However, that is where the metabolic similarities end. Insulin resistance precedes increased glucose levels (Martin et al., 1992), and individuals are classified with "impaired fasting glucose" at levels of $\geq 100 \mathrm{mg} / \mathrm{dL}$ (Genuth et al., 2003). In our study, only the AD group reached that cut-point (Table 1). Although both $\mathrm{AD}$ and PD groups exhibited increased fasting insulin levels, only PD subjects had a significant increase in beta cell function $(\% B)$. Enhanced beta cell function and increased insulin secretion allows normoglycemia to be maintained in response to insulin resistance (Prentki and Nolan, 2006). Because the AD group overall exhibited hyperglycemia, while PD subjects did not, the compensatory increase in fasting insulin levels in the AD group was not sufficient to normalize glucose levels. A greater increase in beta cell function would be necessary to normalize glycemia in $\mathrm{AD}$, and indicates that this group exhibits greater metabolic dysfunction than the PD group. Fasting metabolic data are supported by glucose tolerance analyses. We observed that the AD group had a significantly higher gAUC than the PD group. On the contrary, PD subjects exhibited a significantly higher iAUC than both $\mathrm{AD}$ and $\mathrm{HC}$ subjects. This supports our observation of more severe metabolic impairment in the $\mathrm{AD}$ group vs. a more mild metabolic impairment managed through compensatory insulin secretion in PD.

The degree to which peripheral insulin resistance affects brain insulin resistance is unknown. However, a direct effect of peripheral insulin resistance on the brain is likely due in part to the fact that insulin is involved in cell growth and survival, insulin can readily cross the blood-brain barrier at physiological concentrations (Banks, 2004), and markers of insulin resistance have been shown in the brain of individuals with AD (Talbot et al., 2012). In addition to its known role in peripheral glucose metabolism, studies indicate that insulin is 
involved in neurotransmission, cell survival, and amyloid trafficking (Wan et al., 1997; Gasparini et al., 2001; Skeberdis et al., 2001; van der Heide et al., 2006; Jin et al., 2011). Thus, to determine whether peripheral insulin resistance was related to brain volume in neurodegenerative disease, we analyzed the relationship between insulin resistance (HOMA2) and GMV.

In AD subjects, increased HOMA2 was associated with less GMV in medial temporal brain regions. Within the HC group, we similarly saw that HOMA2 was associated with less GMV, but in frontal cortex. Our findings complement a recent study which reported that, among other regions, the prefrontal and cingulate cortices had less GMV associated with higher HOMA2 in HC individuals (Willette et al., 2013). We did not see a relationship between temporal cortex gray matter and HOMA2 in our elderly group, unlike a recent report by Benedict et al. (2012). However, their cohort was larger $(n=285)$ and older (mean age 75 years) than ours. Our smaller $(n=21)$ and younger group (mean age 71.7 years) may have limited our power to detect smaller relationships between gray matter and insulin resistance in cognitively normal subjects.

When the relationship between HOMA2 and GMV was examined in PD, HOMA2 was associated with greater GMV in the left inferior parietal region. Thus, within the PD group, subjects with greater HOMA2 (and greater compensatory beta cell function) had the highest GMV while subjects with lower HOMA2 had less GMV in this region. This is the first study to analyze the relationship between insulin resistance and GMV in PD, thus we have no comparison for discussion. However, over-activity of the parietal region has been postulated to occur in PD as a mechanism for circumventing impaired circuits in the basal ganglia. For instance, during performance of motor tasks (finger movement), the parietal cortex was overactive in PD subjects compared to controls (Samuel et al., 1997). More recently, connections between the parietal cortex and the cerebellum, pre-motor cortex, and rostral supplementary motor area were shown to be increased in PD compared to controls (Wu et al., 2011), and non-dysphagic PD patients have shown a shift in activation in brain areas including the parietal cortex to compensate for impairment in other motor regions (Suntrup et al., 2013). Although glucose uptake in the brain is primarily insulin-independent in healthy individuals, insulin-dependent glucose uptake may occur in subjects who are insulin resistant (Hirvonen et al., 2011). Our finding of a positive correlation between insulin resistance (with high compensatory insulin secretion) and parietal volume suggests the potential importance of insulin signaling in a brain region that is important in circumventing damaged networks in the basal ganglia.

The current study used an unbiased, voxel-based approach and revealed that in early AD, HOMA2 is associated with less brain volume in the bilateral medial temporal cortex, as well as the temporal and parietal cortices This corroborates our previous ROI approach (Burns et al., 2007) and extends it to other regions where pathologic changes occur early in AD (Braak and Braak, 1991). We further extended our previous findings by evaluating insulin resistance and evaluating PD subjects. However, our results are limited by our small sample size and cross-sectional data, thus future studies with larger groups and longitudinal study designs will be necessary to understand these relationships. We also excluded diabetic subjects (clinical diagnosis or use of an anti-diabetic agent) due to the potential confounding 
effect of diabetic medication on a primary outcome measure (HOMA2). Given that diabetes is a risk factor for $\mathrm{AD}$, exclusion of individuals with severe insulin resistance may have affected our ability to detect a relationship between HOMA2 and cognition. Diabetes status has not been shown to affect the relationship between HOMAIR and GMV in nondemented subjects (Benedict et al., 2012; Willette et al., 2013), but future studies that assess these relationships in diabetic subjects with neurodegenerative disease are needed.

We did not discriminate between PD and PDD, but rather included all PD individuals into a single PD group regardless of dementia status. The reported prevalence of dementia in PD varies widely. It has been shown that on average over $30 \%$ of PD subjects exhibit dementia (Aarsland et al., 2005), but that this number skyrockets to over $75 \%$ when individuals are followed longitudinally (Aarsland et al., 2003). Because the majority of PD subjects will develop cognitive impairment over time following PD diagnosis, we considered them as a single cohort. Larger studies are necessary to discern if the relationship between metabolic function and GMV differs between PD and PDD. An additional limitation of our study was that we analyzed only the relationship between HOMA2 and GMV. Future studies regarding the relationship between insulin resistance and WMV are warranted. Finally, another factor that may play into our findings of increased insulin resistance in neurodegenerative disease is the use of medications in these groups. PD subjects more frequently used levodopa and dopamine agonists, while $\mathrm{AD}$ subjects more often used cholinesterase inhibitors than other groups; thus, their effect cannot be ruled out.

\section{CONCLUSION}

Insulin resistance is increased in non-diabetic $\mathrm{AD}$ and $\mathrm{PD}$ subjects compared to cognitively normal controls; however, individuals with $\mathrm{AD}$ appear to have more severe metabolic dysfunction. HOMA2 was associated with GMV in all groups, but the brain region and directionality of this association differs by diagnosis. Within groups, higher insulin resistance was associated with decreased GMV in healthy control (medial prefrontal) and AD (medial temporal) groups, but increased GMV in PD (parietal) subjects. Our study suggests that the relationship between insulin resistance and brain volume differs between normal aging and neurodegenerative disease. This may be due to differences between aging and disease processes, differing severity of metabolic dysregulation, or a combination of both factors. Our study supports a potential relationship between insulin resistance and brain structure in both normal aging and diagnosed neurodegenerative disease.

\section{Acknowledgments}

\section{FUNDING}

This study was supported by grants R03AG026374 and R21AG029615 from the National Institutes of Aging, grant K23NS058252 from the National Institute on Neurological Disorders and Stroke and a TEVA award from the Kansas City Area Life Sciences Initiative. The University of Kansas General Clinical Research Center (M01RR023940) and the Clinical and Translational Science Unit (UL1 TR000001) provided essential space, expertise, and nursing support. This research was also supported by NIH grant P30AG035982 through the National Institute on Aging and a donation from Henry and Janet Hyndman. E.D.V is supported by KL2 TR000119, R.A.H is supported by K01 AG030514, and J.K.M. is supported by F32 AG044953 and the KU Medical Center Biomedical Research Training Program. 


\section{Abbreviations}
AD
Alzheimer's disease
CDR
Clinical Dementia Rating
DARTEL
Diffeomorphic Anatomical Registration Through Exponentiated Lie algebra
gAUC glucose area under the curve
GMV
gray matter volume
HC
healthy elderly control
HOMA2
homeostasis model assessment of insulin resistance 2
iAUC
insulin area under the curve
IVGTT
intravenous glucose tolerance test
PD
Parkinson's disease
SVC
small-volume correction
TICV
total-intracranial volume
UPDRS
Unified Parkinson's Disease Rating Scale
WMV
white matter volume

\section{References}

Aarsland D, Andersen K, Larsen JP, Lolk A, Kragh-Sorensen P. Prevalence and characteristics of dementia in Parkinson disease: an 8-year prospective study. Arch Neurol. 2003; 60:387-392. [PubMed: 12633150]

Aarsland D, Zaccai J, Brayne C. A systematic review of prevalence studies of dementia in Parkinson's disease. Mov Disord. 2005; 20:1255-1263. [PubMed: 16041803]

Abdul-Ghani MA, Jenkinson CP, Richardson DK, Tripathy D, DeFronzo RA. Insulin secretion and action in subjects with impaired fasting glucose and impaired glucose tolerance: results from the Veterans Administration Genetic Epidemiology Study. Diabetes. 2006; 55:1430-1435. [PubMed: 16644701]

Araki Y, Nomura M, Tanaka H, Yamamoto H, Yamamoto T, Tsukaguchi I, Nakamura H. MRI of the brain in diabetes mellitus. Neuroradiology. 1994; 36:101-103. [PubMed: 8183443]

Ashburner J. A fast diffeomorphic image registration algorithm. Neuroimage. 2007; 38:95-113. [PubMed: 17761438]

Ashburner J, Friston KJ. Unified segmentation. Neuroimage. 2005; 26:839-851. [PubMed: 15955494]

Banks WA. The source of cerebral insulin. Eur J Pharmacol. 2004; 490:5-12. [PubMed: 15094069]

Benedict C, Brooks SJ, Kullberg J, Burgos J, Kempton MJ, Nordenskjold R, Nylander R, Kilander L, Craft S, Larsson EM, Johansson L, Ahlstrom H, Lind L, Schioth HB. Impaired insulin sensitivity as indexed by the HOMA score is associated with deficits in verbal fluency and temporal lobe gray matter volume in the elderly. Diabetes Care. 2012; 35:488-494. [PubMed: 22301128]

Braak H, Braak E. Neuropathological staging of Alzheimer-related changes. Acta Neuropathol (Berl). 1991; 82:239-259. [PubMed: 1759558]

Burns JM, Donnelly JE, Anderson HS, Mayo MS, Spencer-Gardner L, Thomas G, Cronk BB, Haddad Z, Klima D, Hansen D, Brooks WM. Peripheral insulin and brain structure in early Alzheimer disease. Neurology. 2007; 69:1094-1104. [PubMed: 17846409] 
Burns JM, Honea RA, Vidoni ED, Hutfles L, Brooks WM, Swerdlow RH. Insulin is differentially related to cognitive decline and atrophy in Alzheimer's disease and aging. Biochim Biophys Acta. 2011

Burns JM, Honea RA, Vidoni ED, Hutfles LJ, Brooks WM, Swerdlow RH. Insulin is differentially related to cognitive decline and atrophy in Alzheimer's disease and aging. Biochim Biophys Acta. 2012; 1822:333-339. [PubMed: 21745566]

Cheng D, Noble J, Tang MX, Schupf N, Mayeux R, Luchsinger JA. Type 2 diabetes and late-onset Alzheimer's disease. Dement Geriatr Cogn Disord. 2011; 31:424-430. [PubMed: 21757907]

Craft S, Baker LD, Montine TJ, Minoshima S, Watson GS, Claxton A, Arbuckle M, Callaghan M, Tsai E, Plymate SR, Green PS, Leverenz J, Cross D, Gerton B. Intranasal insulin therapy for Alzheimer disease and amnestic mild cognitive impairment: a pilot clinical trial. Arch Neurol. 2012; 69:29_ 38. [PubMed: 21911655]

den Heijer T, Vermeer SE, van Dijk EJ, Prins ND, Koudstaal PJ, Hofman A, Breteler MM. Type 2 diabetes and atrophy of medial temporal lobe structures on brain MRI. Diabetologia. 2003; 46:1604-1610. [PubMed: 14595538]

Dubois B, Burn D, Goetz C, Aarsland D, Brown RG, Broe GA, Dickson D, Duyckaerts C, Cummings J, Gauthier S, Korczyn A, Lees A, Levy R, Litvan I, Mizuno Y, McKeith IG, Olanow CW, Poewe W, Sampaio C, Tolosa E, Emre M. Diagnostic procedures for Parkinson's disease dementia: recommendations from the movement disorder society task force. Mov Disord. 2007; 22:23142324. [PubMed: 18098298]

Gasparini L, Gouras GK, Wang R, Gross RS, Beal MF, Greengard P, Xu H. Stimulation of betaamyloid precursor protein trafficking by insulin reduces intraneuronal beta-amyloid and requires mitogen-activated protein kinase signaling. J Neurosci. 2001; 21:2561-2570. [PubMed: 11306609]

Genuth S, Alberti KG, Bennett P, Buse J, Defronzo R, Kahn R, Kitzmiller J, Knowler WC, Lebovitz H, Lernmark A, Nathan D, Palmer J, Rizza R, Saudek C, Shaw J, Steffes M, Stern M, Tuomilehto J, Zimmet P. Follow-up report on the diagnosis of diabetes mellitus. Diabetes Care. 2003; 26:3160-3167. [PubMed: 14578255]

Hirvonen J, Virtanen KA, Nummenmaa L, Hannukainen JC, Honka MJ, Bucci M, Nesterov SV, Parkkola R, Rinne J, Iozzo P, Nuutila P. Effects of insulin on brain glucose metabolism in impaired glucose tolerance. Diabetes. 2011; 60:443-447. [PubMed: 21270256]

Honea RA, Meyer-Lindenberg A, Hobbs KB, Pezawas L, Mattay VS, Egan MF, Verchinski B, Passingham RE, Weinberger DR, Callicott JH. Is gray matter volume an intermediate phenotype for schizophrenia? A voxel-based morphometry study of patients with schizophrenia and their healthy siblings. Biol Psychiatry. 2008; 63:465-474. [PubMed: 17689500]

Hu G, Jousilahti P, Bidel S, Antikainen R, Tuomilehto J. Type 2 diabetes and the risk of Parkinson's disease. Diabetes Care. 2007; 30:842-847. [PubMed: 17251276]

Hughes AJ, Ben-Shlomo Y, Daniel SE, Lees AJ. What features improve the accuracy of clinical diagnosis in Parkinson's disease: a clinicopathologic study. Neurology. 1992; 42:1142-1146. [PubMed: 1603339]

Jewell JL, Oh E, Ramalingam L, Kalwat MA, Tagliabracci VS, Tackett L, Elmendorf JS, Thurmond DC. Munc18c phosphorylation by the insulin receptor links cell signaling directly to SNARE exocytosis. J Cell Biol. 2011; 193:185-199. [PubMed: 21444687]

Jin Z, Jin Y, Kumar-Mendu S, Degerman E, Groop L, Birnir B. Insulin reduces neuronal excitability by turning on GABA(A) channels that generate tonic current. PLoS One. 2011; 6:e16188. [PubMed: 21264261]

Lee HK, Kumar P, Fu Q, Rosen KM, Querfurth HW. The insulin/Akt signaling pathway is targeted by intracellular beta-amyloid. Mol Biol Cell. 2009; 20:1533-1544. [PubMed: 19144826]

Levy JC, Matthews DR, Hermans MP. Correct homeostasis model assessment (HOMA) evaluation uses the computer program. Diabetes Care. 1998; 21:2191-2192. [PubMed: 9839117]

Liu Y, Liu F, Grundke-Iqbal I, Iqbal K, Gong CX. Deficient brain insulin signalling pathway in Alzheimer's disease and diabetes. J Pathol. 2011; 225:54-62. [PubMed: 21598254]

Martin BC, Warram JH, Krolewski AS, Bergman RN, Soeldner JS, Kahn CR. Role of glucose and insulin resistance in development of type 2 diabetes mellitus: results of a 25-year follow-up study. Lancet. 1992; 340:925-929. [PubMed: 1357346] 
McKhann G, Drachman D, Folstein M, Katzman R, Price D, Stadlan EM. Clinical diagnosis of Alzheimer's disease: report of the NINCDS-ADRDA work group under the auspices of Department of Health and Human Services Task Force on Alzheimer's disease. Neurology. 1984; 34:939-944. [PubMed: 6610841]

Moloney AM, Griffin RJ, Timmons S, O’Connor R, Ravid R, O’Neill C. Defects in IGF-1 receptor, insulin receptor and IRS-1/2 in Alzheimer's disease indicate possible resistance to IGF-1 and insulin signalling. Neurobiol Aging. 2010; 31:224-243. [PubMed: 18479783]

Morris JC. The Clinical Dementia Rating (CDR): current version and scoring rules. Neurology. 1993; 43:2412b-2414. [PubMed: 8232972]

Ott A, Stolk RP, van Harskamp F, Pols HA, Hofman A, Breteler MM. Diabetes mellitus and the risk of dementia: the Rotterdam Study. Neurology. 1999; 53:1937-1942. [PubMed: 10599761]

Prentki M, Nolan CJ. Islet beta cell failure in type 2 diabetes. J Clin Investig. 2006; 116:1802-1812. [PubMed: 16823478]

Ramaker C, Marinus J, Stiggelbout AM, Van Hilten BJ. Systematic evaluation of rating scales for impairment and disability in Parkinson's disease. Mov Disord. 2002; 17:867-876. [PubMed: 12360535]

Reger MA, Watson GS, Green PS, Wilkinson CW, Baker LD, Cholerton B, Fishel MA, Plymate SR, Breitner JC, DeGroodt W, Mehta P, Craft S. Intranasal insulin improves cognition and modulates beta-amyloid in early AD. Neurology. 2008; 70:440-448. [PubMed: 17942819]

Ristow M. Neurodegenerative disorders associated with diabetes mellitus. J Mol Med (Berl). 2004; 82:510-529. [PubMed: 15175861]

Samuel M, Ceballos-Baumann AO, Blin J, Uema T, Boecker H, Passingham RE, Brooks DJ. Evidence for lateral premotor and parietal overactivity in Parkinson's disease during sequential and bimanual movements. A PET study. Brain. 1997; 120(Pt 6):963-976. [PubMed: 9217681]

Schernhammer E, Hansen J, Rugbjerg K, Wermuth L, Ritz B. Diabetes and the risk of developing Parkinson's disease in Denmark. Diabetes Care. 2011; 34:1102-1108. [PubMed: 21411503]

Shirk SD, Mitchell MB, Shaughnessy LW, Sherman JC, Locascio JJ, Weintraub S, Atri A. A webbased normative calculator for the uniform data set (UDS) neuropsychological test battery. Alzheimer's Res Ther. 2011; 3:32. [PubMed: 22078663]

Simon KC, Chen H, Schwarzschild M, Ascherio A. Hypertension, hypercholesterolemia, diabetes, and risk of Parkinson disease. Neurology. 2007; 69:1688-1695. [PubMed: 17761552]

Skeberdis VA, Lan J, Zheng X, Zukin RS, Bennett MV. Insulin promotes rapid delivery of $N$-methylD-aspartate receptors to the cell surface by exocytosis. Proc Natl Acad Sci U S A. 2001; 98:35613566. [PubMed: 11248117]

Steen E, Terry BM, Rivera EJ, Cannon JL, Neely TR, Tavares R, Xu XJ, Wands JR, de la Monte SM. Impaired insulin and insulin-like growth factor expression and signaling mechanisms in Alzheimer's disease-is this type 3 diabetes? J Alzheimer's Dis. 2005; 7:63-80. [PubMed: 15750215]

Suntrup S, Teismann I, Bejer J, Suttrup I, Winkels M, Mehler D, Pantev C, Dziewas R, Warnecke T. Evidence for adaptive cortical changes in swallowing in Parkinson's disease. Brain. 2013; 136:726-738. [PubMed: 23412935]

Takahashi M, Yamada T, Tooyama I, Moroo I, Kimura H, Yamamoto T, Okada H. Insulin receptor mRNA in the substantia nigra in Parkinson's disease. Neurosci Lett. 1996; 204:201-204. [PubMed: 8938265]

Talbot K, Wang HY, Kazi H, Han LY, Bakshi KP, Stucky A, Fuino RL, Kawaguchi KR, Samoyedny AJ, Wilson RS, Arvanitakis Z, Schneider JA, Wolf BA, Bennett DA, Trojanowski JQ, Arnold SE. Demonstrated brain insulin resistance in Alzheimer's disease patients is associated with IGF-1 resistance, IRS-1 dysregulation, and cognitive decline. J Clin Investig. 2012; 122:1316-1338. [PubMed: 22476197]

Thambisetty M, Metter EJ, Yang A, Dolan H, Marano C, Zonderman AB, Troncoso JC, Zhou Y, Wong DF, Ferrucci L, Egan J, Resnick SM, O’Brien RJ. Glucose intolerance, insulin resistance, and pathological features of alzheimer disease in the baltimore longitudinal study of aging. JAMA Neurol. 2013; 70:1167-1172. [PubMed: 23897112] 
Turner RC, Holman RR. Insulin rather than glucose homoeostasis in the pathophysiology of diabetes. Lancet. 1976; 1:1272-1274. [PubMed: 73696]

van der Heide LP, Ramakers GMJ, Smidt MP. Insulin signaling in the central nervous system: learning to survive. Prog Neurobiol. 2006; 79:205-221. [PubMed: 16916571]

Wallace TM, Levy JC, Matthews DR. Use and abuse of HOMA modeling. Diabetes Care. 2004; 27:1487-1495. [PubMed: 15161807]

Wan Q, Xiong ZG, Man HY, Ackerley CA, Braunton J, Lu WY, Becker LE, MacDonald JF, Wang YT. Recruitment of functional GABA(A) receptors to postsynaptic domains by insulin. Nature. 1997; 388:686-690. [PubMed: 9262404]

Weintraub S, Salmon D, Mercaldo N, Ferris S, Graff-Radford NR, Chui H, Cummings J, DeCarli C, Foster NL, Galasko D, Peskind E, Dietrich W, Beekly DL, Kukull WA, Morris JC. The Alzheimer's Disease Centers' Uniform Data Set (UDS): the neuropsychologic test battery. Alzheimer Dis Assoc Disord. 2009; 23:91-101. [PubMed: 19474567]

Willette AA, Xu G, Johnson SC, Birdsill AC, Jonaitis EM, Sager MA, Hermann BP, La Rue A, Asthana S, Bendlin BB. Insulin resistance, brain atrophy, and cognitive performance in late middle-aged adults. Diabetes Care. 2013; 36:443-449. [PubMed: 23069842]

Wu T, Wang L, Hallett M, Chen Y, Li K, Chan P. Effective connectivity of brain networks during selfinitiated movement in Parkinson's disease. Neuroimage. 2011; 55:204-215. [PubMed: 21126588]

Xu W, Qiu C, Gatz M, Pedersen NL, Johansson B, Fratiglioni L. Mid- and late-life diabetes in relation to the risk of dementia: a population-based twin study. Diabetes. 2009; 58:71-77. [PubMed: 18952836]

Xu Q, Park Y, Huang X, Hollenbeck A, Blair A, Schatzkin A, Chen H. Diabetes and risk of Parkinson's disease. Diabetes Care. 2011; 34:910-915. [PubMed: 21378214] 

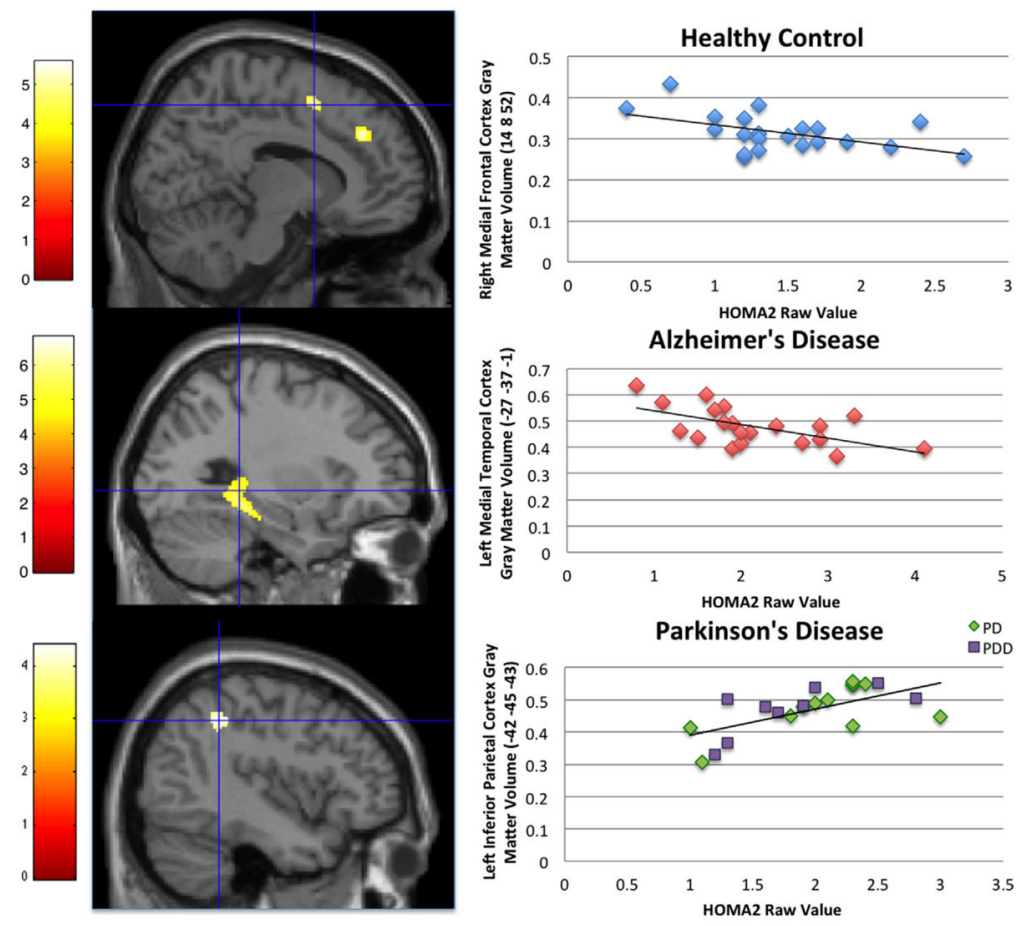

Fig. 1.

Relationship between higher HOMA2 and regional gray matter volume at cross-section in healthy control, AD, and PD individuals. The color bar represents $t$ values. Statistical parametric maps are overlaid on a canonical brain image. Cross-hairs are on the most significant cluster from the HOMA2 regression. Significant clusters from these three analyses were extracted and plotted against raw HOMA2 values for visual purposes. The coordinates for our voxel-based morphometry results are presented in MNI space. (For interpretation of the references to color in this figure legend, the reader is referred to the web version of this article.) 


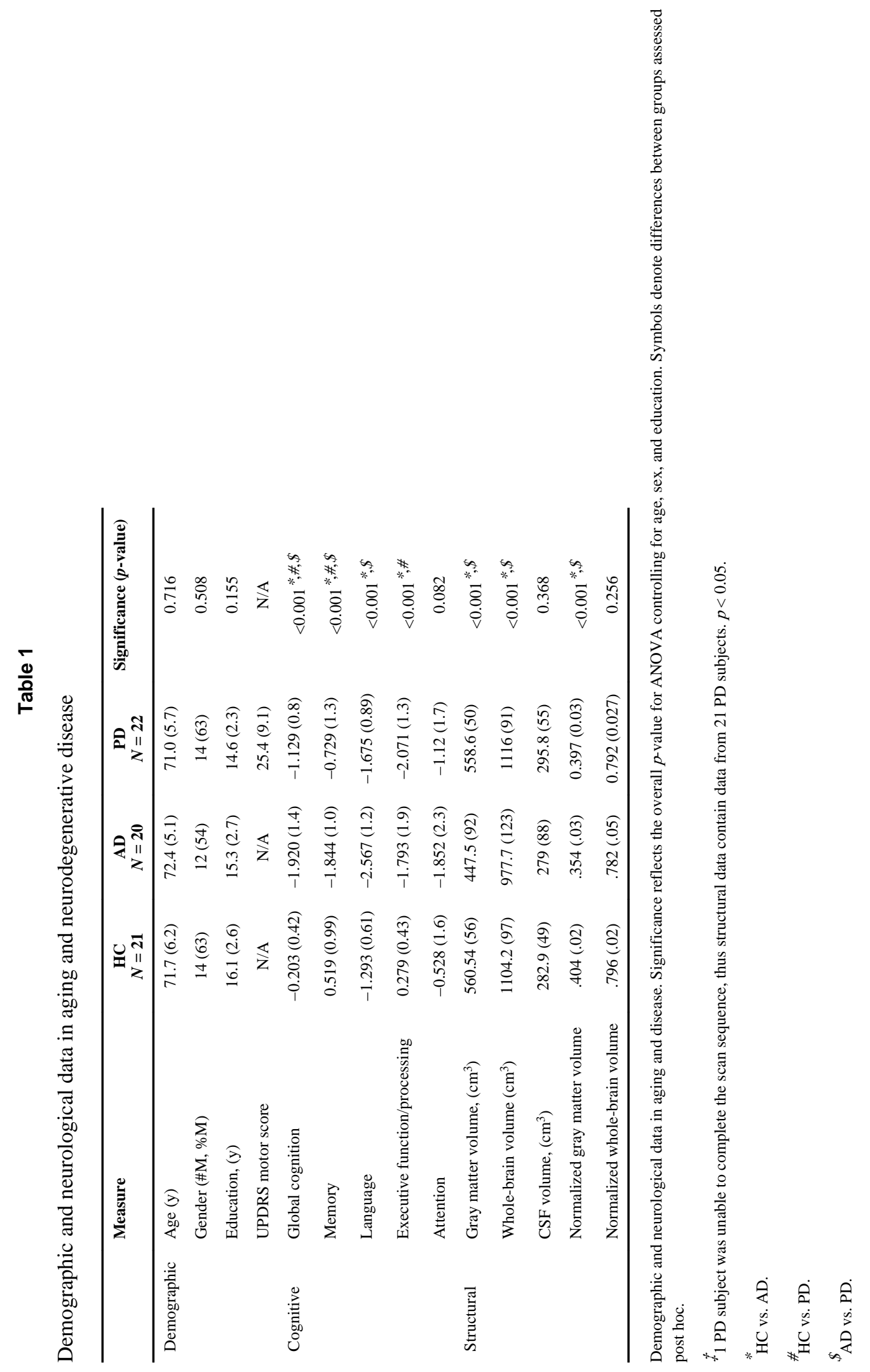


Table 2

Metabolic differences between diagnosis groups

\begin{tabular}{lllll}
\hline Measure & $\begin{array}{l}\text { HC } \\
\boldsymbol{N}=\mathbf{2 1}\end{array}$ & $\begin{array}{l}\text { AD } \\
\boldsymbol{N}=\mathbf{2 0}\end{array}$ & $\begin{array}{l}\text { PD } \\
\boldsymbol{N}=\mathbf{2 2}\end{array}$ & Significance $(\boldsymbol{p}$-value $)$ \\
\hline Weight (kg) & $74.1(14.5)$ & $73.2(15.6)$ & $77.0(17.9)$ & 0.812 \\
BMI & $26.1(3.8)$ & $25.3(5.4)$ & $26.6(3.4)$ & 0.814 \\
Systolic BP & $125.6(21.5)$ & $136.6(22.3)$ & $121.0(15.5)$ & $0.028^{\$}$ \\
Diastolic BP & $72.7(9.1)$ & $73.6(8.6)$ & $73.4(9.8)$ & 0.814 \\
Hypertensive subjects (\#, \%) & $5(23.8 \%)$ & $7(33.3 \%)$ & $3(13.6 \%)$ & 0.313 \\
HOMA2 (Insulin Resistance) & $1.45(0.54)$ & $2.15(.81)$ & $2.04(0.69)$ & $0.004^{*}, \#$ \\
Fasting Glucose (mg/dL) & $93.4(4.6)$ & $102.4(14.5)$ & $92.1(6.3)$ & $<0.001^{*}, \$$ \\
Fasting Insulin ( $\mu \mathrm{U} / \mathrm{mL})$ & $10.95(4.3)$ & $16.25(5.9)$ & $15.8(5.5)$ & $0.002^{*}, \#$ \\
\% B (Beta cell function) & $112.6(30.6)$ & $128.4(36.3)$ & $146.8(31.7)$ & $0.03^{\#}$ \\
2-h Glucose AUC (gAUC) & $16174.6(1674)$ & $17771.1(3323)$ & $15868.6(2163.8)$ & $0.017^{\$}$ \\
2-h Insulin AUC (iAUC) & $3126(1559)$ & $3613(1360)$ & $4509.1(1940.4)$ & $0.038^{\#}$ \\
\hline
\end{tabular}

Metabolic differences between diagnosis groups. Significance reflects the overall $p$-value for ANOVA controlling for age, sex, and education. Symbols denote differences between groups assessed post hoc.

$F_{1}$ PD subject was unable to complete the scan sequence, thus structural data contain data from 21 PD subjects. $p<0.05$.

HC vs. AD.

${ }^{\#}$ HC vs. PD.

${ }_{\text {AD vs. PD. }}$ 


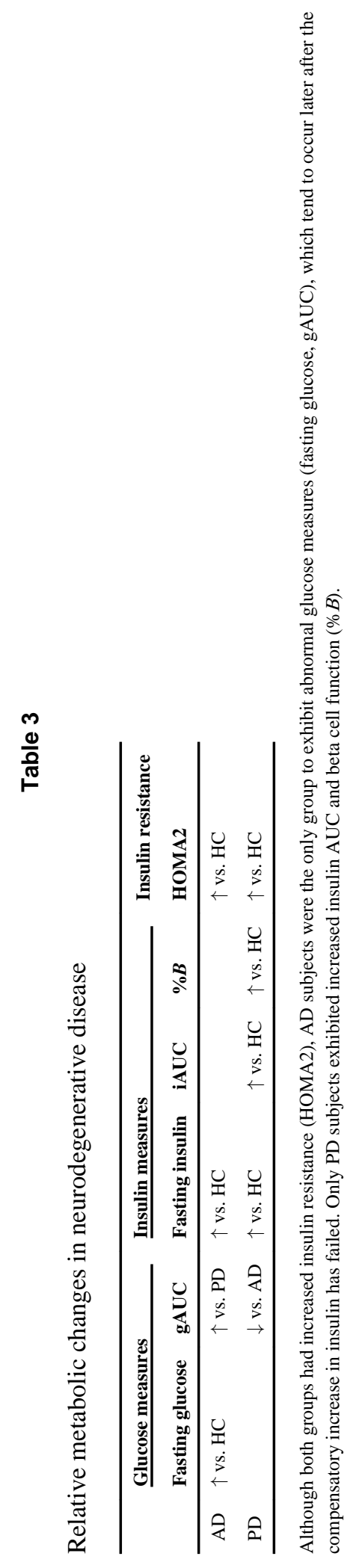

Neuroscience. Author manuscript; available in PMC 2015 June 13. 


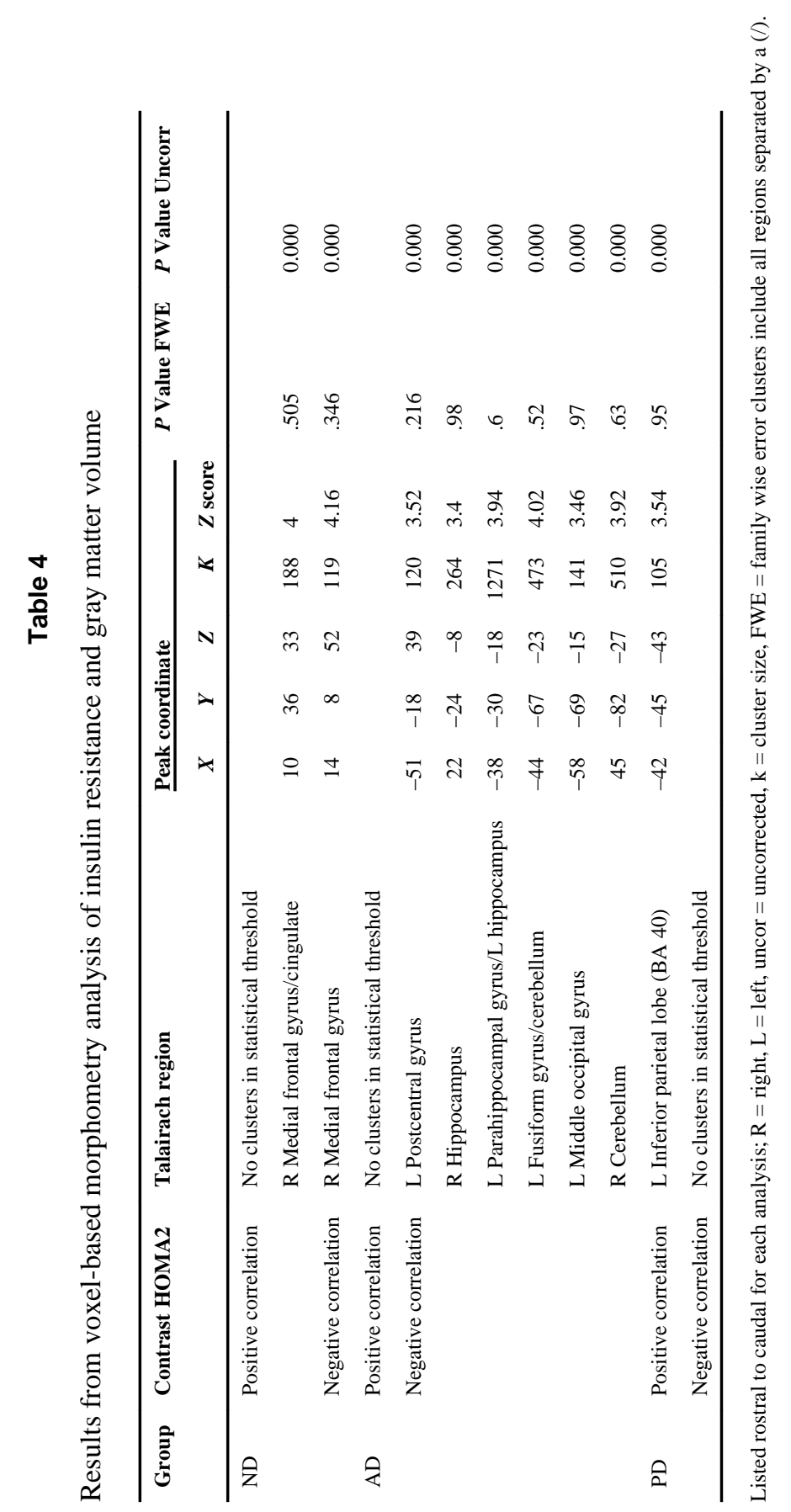

